\title{
AFrágil Gênese da Tutela Jurídica do Meio Ambiente no Sistema Multilateral de Comércio: uma análise do período de Bretton Woods à Rodada de Tóquio (1947-1979)
}

\author{
The Fragile Genesis of the Environmental Protection in the Multilateral \\ Trading System: an analysis of the period comprising Bretton Woods to the \\ Tokyo Round (1947-1979)
}

\author{
Arno Dal Ri Jr. \\ Universidade Federal de Santa Catarina, Florianópolis - SC, Brasil \\ Mariana Clara de Andrade \\ Universidade Federal de Santa Catarina, Florianópolis - SC, Brasil
}

\begin{abstract}
Resumo: o presente artigo tem por objetivo estudar os traços iniciais das discussões sobre questões ambientais no âmbito do Acordo Geral sobre Tarifas e Comércio (GATT), durante o período compreendido desde as negociações da pretendida carta da Organização Internacional do Comércio (ITO), em 1947, até o final da Rodada de Tóquio, em 1979. Para tanto, foram analisados principalmente os textos dos acordos da época e os documentos produzidos nas rodadas de negociação. $\mathrm{O}$ estudo desse período mostra-se relevante por esboçar as origens de uma discussão que viria a ganhar força nos anos subsequentes, repercutindo até os dias atuais.
\end{abstract}

Palavras-chave: Sistema Multilateral de Comércio.GATT. Meio Ambiente. Rodada de Tóquio.Negociações.
Abstract: the present paper analyses the first traces of the debates on environmental issues in the context of the General Agreement on Tariffs and Trade (GATT), in the period that comprehends the negotiations of the charter of the intended International Trade Organization (ITO), 1947, until the end of the Tokyo Round, 1979. In order to assess this subject, this paper mainly refers to the texts of the agreements of the mentioned period and the documents produced during the negotiation rounds. The study of these three initial decades is relevant for a full grasp of the origins of a discussion that would gain strength in the subsequent years, and that rebounds until the present days.

Keywords: Multilateral Trading System.GATT. Environment. Tokyo Round. Negotiations.

Recebido em: 09/01/2016

Revisado em: 13/06/2016

Aprovado em: 20/06/2016 


\section{Introdução}

Poucos temas atualmente suscitam tanta mobilização da comunidade internacional quanto a tutela jurídica do meio ambiente. Desde 1972, quando teve início a primeira grande reunião sobre o tema, promovida pela Organização das Nações Unidas (ONU), a "Conferência Mundial sobre o Ambiente Humano", ou Conferência de Estocolmo, verificou-se uma multiplicação de encontros internacionais relativos ao debate e à criação de acordos sobre a proteção ambientalem nível multilateral. Uma das áreas mais sensíveis a essa discussão é, particularmente, o comércio internacional. Por tal motivo, um dos principais temas de negociação da atual Rodada de Doha, promovida pelo grupo da Organização Mundial do Comércio (OMC) é a interação entre liberalização comercial e proteção ambiental.

Esse debate promovido pela OMC, contudo, encontra alguns antecedentes já nas rodadas de negociação que se encontram na origem da organização. Ainda que com uma linguagem primária e com intenções originais muito distintas das que permeiam a interpretação dos dispositivos atualmente, o texto do Acordo Geral sobre Tarifas Aduaneiras e Comércio (GATT), em 1947, já previa como exceção às suas normas eventuais medidas "necessárias à proteção da saúde e da vida das pessoas e dos animais e à preservação dos vegetais" ou "relativas à conservação dos recursos naturais esgotáveis, se tais medidas forem aplicadas conjuntamente com restrições à produção ou ao consumo nacionais". Contudo, os motivos que levaram a tais redações foram muito distintos daqueles invocados hoje pelos Estados quando lançam mão das Exceções Gerais do artigo XX do GATT.

Ainda assim, foi a partir dessa redação, seguindo a lógica da não discriminação operante no sistema multilateral de comércio e acompanhando as atualizações nas discussões internacionais sobre proteção ambiental, o meio ambiente gradativamente ganhou espaço nas negociações comerciais que se seguiram até a entrada em funcionamento da OMC, em 1995, quando os acordos produzidos em tais rodadas foram consolidados em um package único. Atualmente, o tema ganha ainda outras nuances não vislumbradas no decorrer das décadas até 1995 além daquelas relati- 
vas às barreiras tarifárias e não tarifárias ao comércio internacional, como a interação de acordos internacionais ambientais -Multilateral Environmental Agreements(MEAs) com as normas da OMC.

Nesse contexto, o objetivo do presente artigo é analisar o desenvolvimento das discussões relativas ao meio ambiente no contexto do sistema multilateral de comércio até o final da Rodada de Tóquio, em 1979. Para realizar esse estudo, foram analisados principalmente os textos dos acordos realizados no período, tais como a Carta de Havana e o próprio texto do Acordo Geral sobre Tarifas e Comércio, e os documentos referentes aos trabalhos preparatórios e às rodadas de negociação. Eventuais comparações das redações originais com as atualmente vigentes também são realizadas ao longo do trabalho.

O recorte histórico deste trabalho justifica-se, metodologicamente, pelo fato de que, no decorrer da Rodada do Uruguai, intensifica-se a produção normativa no âmbito do sistema GATT, de modo a aportar grandes modificações na estrutura do sistema multilateral de comércio. Dessa forma, prezando pelo detalhamento da descrição desse histórico sem, contudo, produzir um trabalho excessivamente carregado de informações, optou-se por dividi-lo em três partes.

Para uma melhor didática do trabalho, explanar-se-á brevemente o histórico e a estrutura do sistema GATT, a fim de que, nas seções subsequentes, a compreensão das rodadas de negociação fique mais clara. A segunda parte adentra propriamente no tema objeto deste trabalho, qual seja, a tutela ambiental no sistema GATT/OMC, narrando as origens das primeiras disposições do Acordo Geral Sobre Tarifas Aduaneiras e Comércio a tratarem do assunto. A terceira parte trata das Rodadas de Negociação a partir da década de 1970, quando efetivamente as discussões ambientais ganharam seus primeiros contornos no sistema multilateral de comércio, até o final da supracitada Rodada de Tóquio, em 1979. Serão analisados, além dos acordos pertinentes desenvolvidos em cada período e da doutrina relevante ao tema, os trabalhos preparatórios e o contexto vigente à época de cada período.

A relevância deste estudo está relacionada à elucidação do desenvolvimento das discussões ambientais no sistema multilateral de comércio. 
Com a análise aqui realizada, é possível verificar, particularmente, a origem de limitações encontradas atualmente quando litígios são levados ao sistema de solução de controvérsias da OMC, assim como tal leitura permite que se vislumbre a interpretação evolutiva por trás de conceitos relativos a questões ambientais do $\mathrm{GATT}^{1}$.A clarificação desse histórico pode servir, ainda, a uma compreensão mais aprofundada dos motivos que ensejaram a criação de determinados acordos do guarda-chuva no âmbito do GATT e, após, na própria OMC, assim como auxilia a obter uma visão global do desenvolvimento da questão na Organização.

\section{Breve Introdução ao Sistema GATT}

A consolidação do atual sistema multilateral de comércio internacional foi uma construção histórica e gradual que remonta à regulamentação das relações comerciais posteriores à Segunda Grande Guerra. Ao final desta observou-se um movimento que buscava a liberalização do comércio internacional na tentativa de combater o sistema protecionista vigente até então em âmbito mundial. Em 1944, com a realização da Conferência de Bretton Woods, esta nova perspectiva do direito do comércio internacional começava a ganhar materialidade como ordenamento jurídico. Dos acordos realizados nessa ocasião surgiram duas instituições internacionais: o Fundo Monetário Internacional (FMI) e o grupo do Banco Mundial(BM) ${ }^{2}$. Além dessas duas entidades, surgiu, durante a Conferência de Havana (1947-1948), o projeto de construção da Organização Internacional do Comércio - International Trade Organization (ITO), uma terceira instituição que se uniria ao FMI e ao Banco Mundial como uma agência especializada da ONU. Enquanto as duas primeiras instituições

\footnotetext{
${ }^{1}$ O termo "evolução interpretativa" foi utilizado pelo Órgão de Apelação no caso US Shrimp, em 2001, justamente para se referir à mudança de perspectiva que o artigo XX $(\mathrm{g})$, que versa sobre questões ambientais, sofreu desde a sua redação. Cf. WT/DS58/AB/R.

2 Composto primordialmente por duas organizações - o Banco Internacional para Reconstrução e Desenvolvimento (BIRD) e a Associação Internacional de Desenvolvimento (IAD). Ademais, três outros órgãos fazem parte de sua estrutura: a Sociedade Financeira Internacional (SFI), a Agência Multilateral de Garantia de Investimentos (MIGA) e o Centro Internacional para Arbitragem de Disputas sobre Investimentos (ICSID). (WORLD BANK, 2014).
} 
estavam ligadas ao sistema financeiro internacional, a ITO buscaria uma gradual solidificação de um sistema regulatório a fim de mitigar as barreiras ao comércio internacional (DAL RI JR., 2004, p. 121).

Caberia àITO administrar a implementação da chamada "Carta de Havana", documento de natureza multilateral a qual dispunha amplamente sobre o sistema regulatório de comércio internacional, visando à redução de tarifas, quotas e preferências, além de disciplinar outros mecanismos deregulação ao comércio, inclusive com a previsão de um sistema de solução pacífica de controvérsias (VANGRASSTEK, 2013, p. 43-44). Essas disposições "materiais" (contendo obrigações sobre reduções tarifárias e outras medidas de liberalização de comércio) não estariam, contudo, propriamente dispostas na Carta da ITO, mas sim em um protocolo a ela anexo (IRWIN; MAVROIDIS; SYKES, 2008, p. 74). Esse protocolo, que viria a ser chamado de Acordo Geral sobre Tarifas Aduaneiras e Comércio (o já mencionado GATT ${ }^{3}$ ), entraria em vigor antes e de maneira independente da Carta da ITO (IRWIN; MAVROIDIS; SYKES, 2008, p. 74). A decisão a favor de um acordo provisório, o GATT, assim como o primeiro modelo da Carta da ITO, foi tomada em Londres, em 1946, durante First Preparatory Meeting (IRWIN; MAVROIDIS; SYKES, 2008, p. 77-80)4 .

Após esse encontro ocorreu, em Nova Iorque, uma conferência no intuito de iniciar a negociação em torno às reduções tarifárias, buscando a liberalização do comércio multilateral (HOEKMAN; MAVROIDIS, 2007, p. 7) ${ }^{5}$. Por meio desta surgia, efetivamente, o GATT, cujas negociações se concluíram em 1947, com 23 países envolvidos - dentre os quais figurava o Brasil -, tendo entrado em vigor em 1948, e que vigeria até o efetivo funcionamento da Carta de Havana (HOEKMAN; MAVROIDIS, 2007,

\footnotetext{
${ }^{3}$ Do inglês, General Agreement on Tariffs and Trade.

${ }^{4}$ As negociações seguintes até a versão final do definitiva, que duraram de 1946 a 1948 , ocorreram nos também chamados Preparatory Committees para a ITO em Nova Iorque, Genebra e, finalmente, Havana.

${ }^{5}$ Ressalte-se que os dois movimentos foram essencialmente articulados pelos Estados Unidos, a partir de uma longa negociação com o Reino Unido, e os dois movimentos (Bretton Woods e as negociações das reduções tarifárias) possuíam comitês trabalhando em conjunto. Para uma leitura detalhada do histórico de negociações e da gênesis do GATT, cf. Irwin, Mavroidis e Sykes (2008).
} 
p. 8) ${ }^{6}$. Esse acordo foi articulado principalmente pelos Estados Unidos, tendo por objetivo a redução recíproca de tarifas comerciais (STOLL; SCHORKOPF, 2007, p. 12). Devido ao fato de ter sido finalizado com status de documento preliminar, a ser posteriormente integrado à carta da ITO - sendo que algumas matérias seriam tratadas somente por esta última -, as disposições do GATT eram de certa maneira limitadas ${ }^{7}$.

Ocorre que, apesar da efetivação do Banco Mundial e do FMI, a ITO não logrou êxito em sua constituição ${ }^{8}$, pois - como não é estranho à história das organizações internacionais - o Congresso estadunidense não ratificou a Carta de Havana (VANGRASSTEK, 2013, p. 44). Desse modo, diz-se que o GATT nasceu como uma "medida provisória" (DAL RI JR., 2004, p. 135), cujas disposições deveriam viger somente até a entrada em funcionamento da $\mathrm{ITO}^{9}$, mas que acabou por se tornar o aparelho normativo primordial do comércio internacional até a fundação da OMC, quando por esta foi incorporado. Essa limitação das disposições do GATT em parte explica algumas problemáticas textuais mencionadas neste trabalho.

${ }^{6} \mathrm{O}$ objetivo dessa medida seria salvaguardar as concessões tarifárias durante as negociações da ITO (IRWIN; MAVROIDIS; SYKES, 2008, p. 99).

${ }^{7}$ Nas palavras de Irwin, Mavroidis e Sykes (2008, p. 96), “[t]he GATT was not a treaty or an organization, but merely a trade agreement put into effect by executive order".

${ }^{8}$ Dal Ri Jr. aponta "[...] três fatores estruturais que concorreram para o insucesso da iniciativa: a) a mudança da situação mundial entre 1945 e 1960; b) a mudança da situação política nos Estados Unidos no final da década de quarenta; e c) os "defeitos" da Carta, que provocaram a ferrenha oposição de setores da economia norte-americana". A partir disso, "'[o] fato de o governo norte-americano ter retirado apoio à iniciativa representou o fim de qualquer possibilidade de sobrevivência do projeto da Carta de Havana e da Organização Internacional do Comércio. Sem a colaboração dos Estados Unidos, maior financiador do projeto e já naquela época responsável por grande parte dos fluxos comerciais internacionais, seria impensável levar adiante um projeto daquelas dimensões". (DAL RI JR,, 2004, p. 127 e 128-129).

${ }^{9}$ O artigo XXIX.2 do GATT/47 previa: "A aplicação de Parte II [Artigo III ao Artigo XXIV] deste Acordo será suspensa no dia em que a Carta de Havana entrar em vigor" (MDIC, 1994, GATT). O artigo XXIX previa a relação do GATT com a Carta de Havana. Particularmente, o artigo XXIX.6 dispunha a prevalência da Carta de Havana perante as obrigações do GATT/47. 
A finalização do texto do GATT inaugurou ainda uma sucessão de rodadas de negociação ${ }^{10}$ entre diversos países $^{11}$, as quais buscavam precisamente delimitar as novas perspectivas referentes ao já descrito movimento de liberalização do comércio internacional. A primeira delas, em 1947, Genebra, tinha por objetivo primordial, assim como as quatro rodadas subsequentes, a redução ou eliminação de tarifas alfandegárias em prol da circulação de bens. Esse objetivo guiou os encontros até a rodada inaugurada em 1964.

De 1964 em diante - na Rodada Kennedy - as negociações também passaram a abranger tópicos relativos a barreiras não tarifárias. Esses novos objetivos deram azo à busca por um sistema mais complexo do que o texto do GATT, o qual não dispunha de umarcabouço satisfatório para a diminuição desses outros obstáculos (VAN DEN BOSSCHE, 2005, p. 82) ${ }^{12}$. Os novos acordos concluídos no bojo dessas negociações eram, contudo, obrigações à parte do GATT (STOLL; SCHORKOPF, 2006, p. 13).

O apogeu das rodadas de negociação se deu com a Rodada do Uruguai, a qual, originalmente programada para durar quatro anos, foi de setembro de 1986 a dezembro de 1993 (VANGRASSTEK, 2013, p. 45). Essa rodada havia sido concebida com o intento de iniciarnegociações mais abrangentes, e dentre suas grandes inovações está o início de negociações relativas também ao comércio de serviços (além dos já discutidos temas sobre comércio de produtos de agricultura, têxteis e vestimentas) (HOEKMAN; MAVROIDIS, 2007, p. 12). Nessa rodada estabeleceu-se também o GATT/94, em substituição ao GATT/47, o qual adicionou alguns instrumentos legais ao texto e implementou também uma série de

${ }^{10}$ Tais foram as rodadas: Genebra (1947), Annecy (1949), Torquay (1951), Dillon Round (1960-1961), Kennedy Round (1964-1967), Tokyo Round (1973-1979) e Uruguay Round (1986-1994).

${ }^{11} \mathrm{Na}$ primeira rodada, em 1947, 23 países estavam presentes. O sistema foi ganhando gradual apoio e participação internacional, sendo que a atual Rodada de Doha, inaugurada em 2001, conta com mais de 150 participantes (HOEKMAN; MAVROIDIS, 2007, p. 9). ${ }^{12} \mathrm{O}$ autor ressalta ainda: "In spite of its scant institutional framework, the GATT was very successful in reducing tariffs on trade in goods, in particular on industrial goods from developed countries. In eight negotiating rounds between 1947 and 1994, the average level of tariffs of developed countries on industrial products was brought down from over 40 per cent to less than 4 per cent." (VAN DEN BOSSCHE, 2005, p. 81-82). 
decisões tomadas pelas suas partes contratantes (IRWIN; MAVROIDIS; SYKES, 2008, p. 103 e 119) ${ }^{13}$, mas não modificou suas provisões. Assim, o texto permaneceu praticamente inalterado em relação à versão de 1947.

Finalmente, excedendo as expectativas da rodada (que já não eram modestas), o roundculminou com a instituição da Organização Mundial do Comércio, em um processo de acordos entre os países negociadores que durou de 1990 (quando o Canadá formalmente sugeriu a instituição de uma organização) a 1993 (quando os Estados Unidos, que apresentavam maior relutância ao projeto, aceitaram-no finalmente) ${ }^{14}$.

A OMC apossou-se do pacote de acordos que haviam se unificado ao sistema GATT, institucionalizando-o definitivamente ${ }^{15}$. Atualmente, a OMC está consolidada como a principal organização a lidar com normas de mercado internacional entre Estados (WTO, 2016b), dispondo do já referido robusto aparato normativo, de um eficaz mecanismo de resolução de litígios ${ }^{16}$ e supervisão de políticas de comércio internacional. Além disso, a organização também suplantou as negociações do GATT, dando continuidade às rodadas de negociações e tornando-se o próprio foro para a sua consecução.

\section{Negociações Iniciais do Sistema Multilateral de Comércio: ori- gens das atuais provisões ambientais no GATT}

O primeiro rascunho do texto do GATT foi obtido no Preparatory Committee, realizadoem Londres, em 1946, e então chamado de London

\footnotetext{
${ }^{13}$ Essa distinção está inclusive positivada pelo Acordo Constitutivo da OMC, em seu artigo II.4.

${ }^{14} \mathrm{O}$ histórico de consolidação desse projeto na Rodada do Uruguai é descrito com clareza por Van Den Bossche (2005, p. 83- 85).

${ }^{15}$ De fato, uma das grandes diferenças entre GATT/47 e o sistema da OMC, conforme anotam Hoekman e Mavroidis, é justamente o aspecto estrutural que a organização recebeu, uma vez que fazer parte da OMC significa a aceitação de todas as provisões de seus Acordos Multilaterais, enquanto no sistema GATT cada membro decidia de quais provisões e acordos abrangidos participaria (HOEKMAN; MAVROIDIS, 2007, p. 29).

${ }^{16}$ Cameron e Gray (2001, p. 249 e ss.) comentam brevemente elementos para a eficácia do sistema de resolução de litígios da $\mathrm{OMC}$ e a sua credibilidade.
} 
Draft, tendo sido posteriormente rediscutido nos Drafting Committees em Nova Iorque, Genebra e Havana. Em Genebra, 1947, o texto teve sua versão final concluída - o GATT Final Act -, tendo sido posteriormente modificado em Havana (IRWIN; MAVROIDIS; SYKES, 2008, p. 103). Cabe ressaltar que o London Draft, por sua vez, foi baseado em um texto inicial sugerido pelos Estados Unidos (doravante, Suggested Charter), fruto de uma extensa negociação bilateral com o Reino Unido, e que serviu de fundamento ao início das negociações (IRWIN; MAVROIDIS; SYKES, 2008, p. 104). Dessa forma, evidentemente o cenário original dos trabalhos era amplamente favorável ao interesse das duas grandes potências, países industrializados e desenvolvidos.

As redações das Cartas de Londres, Genebra, Nova Iorque e Havana, assim como o próprio GATT/47, não previam em seus respectivos preâmbulos ou objetivos a preservação ambiental ou dos recursos naturais. Os textos obtidos nas negociações de 1946 a 1947, que culminaram na Carta de Havana, igualmente objetivavam apenas a expansão do comércio internacional, a fim de manter a paz mundial e auxiliar o desenvolvimento econômico dos participantes. Nada se mencionava acerca de preservação de recursos naturais ou desenvolvimento sustentável (mesmo porque este último termo viria a ser cunhado apenas em 1987).

Uma disposição semelhante, no âmbito da OMC, veio positivada apenas pelo Acordo Constitutivo da Organização Mundial do Comércio, em 1994, reconhecendo a necessidade de se permitir "ao mesmo tempo a utilização ótima dos recursos mundiais em conformidade com o objetivo de um desenvolvimento sustentável e buscando proteger e preservar o meio ambiente e incrementar os meios para fazê-lo" (MDIC, Acordo Constitutivo da $\mathrm{OMC}^{17}$.

\footnotetext{
${ }^{17}$ Em comparação a esse trecho, o GATT/47, por exemplo, determinava em seu preâmbulo apenas o reconhecimento de que "[...] suas relações no domínio comercial e econômico devem ser orientadas no sentido de elevar os padrões de vida, de assegurar o emprego pleno e um alto e sempre crescente nível de rendimento real e de procura efetiva, para a mais ampla exploração dos recursos mundiais e a expansão da produção e das trocas de mercadorias." (MDIC, GATT/47).
} 
O artigo XX é o único dispositivo no GATT/47 a trazer elementos relacionados ao meio ambiente, em suas alíneas (b) e (g). As provisões correspondentes, nos textos que precederam o GATT, são o artigo 32 da Suggested Charter; o artigo 37 do London e do New York Drafts, oartigo 43 do Geneva Draft e o artigo 45 da Carta de Havana (WTO, 2012, p. 596).

A atual redação do artigo XX, alíneas (b) e (g), assim dispõe:

Desde que essas medidas não sejam aplicadas de forma a constituir quer um meio de discriminação arbitrária, ou injustificada, entre os países onde existem as mesmas condições, quer uma restrição disfarçada ao comércio internacional, disposição alguma do presente capítulo será interpretada como impedindo a adoção ou aplicação, por qualquer Parte Contratante, das medidas:

$[\ldots]$

(b) necessárias à proteção da saúde e da vida das pessoas e dos animais e à preservação dos vegetais;

$[\ldots]$

(g) relativas à conservação dos recursos naturais esgotáveis, se tais medidas forem aplicadas conjuntamente com restrições à produção ou ao consumo nacionais. (MDIC, GATT/47) ${ }^{18}$

Em contraste, a redação original das alíneas correspondentes do artigo 32 (General Exceptions do Chapter IV) da Suggested Charter, assim determinavam:

\footnotetext{
${ }^{18} \mathrm{O}$ texto original em inglês assim dispõe: "Subject to the requirement that such measures are not applied in a manner which would constitute a means of arbitrary or unjustifiable discrimination between countries where the same conditions prevail, or a disguised restriction on international trade, nothing in this Agreement shall be construed to prevent the adoption or enforcement by any contracting party of measures: [...] (b) necessary to protect human, animal or plant life or health; [...] (g) relating to the conservation of exhaustible natural resources if such measures are made effective in conjunction with restrictions on domestic production or consumption. (WTO, 2012, p. 562).
} 
Artigo 32. Exceções Gerais ao Capítulo IV

Disposição alguma do presente capítulo será interpretada como impedindo a adoção ou aplicação, por qualquer Parte Contratante, das medidas

$[\ldots]$

b. necessárias à proteção da saúde e da vida das pessoas e dos animais e à preservação dos vegetais

$[\ldots]$

j. relativas à conservação dos recursos naturais esgotáveis, se tais medidas forem tomadas conforme acordo internacional ou forem aplicadas conjuntamente com restrições à produção ou ao consumo nacionais. (U.S. Department of State, 1946, p. 24, grifo nosso) ${ }^{19}$

Como é possível observar, apesar de a redação da alínea (b) não ter sido modificada, a redação da alínea (g) (equivalente, originalmente, à alínea (j) do artigo 32) foi, por sua vez, sensivelmente alterada. Ainda que tenha havido apenas a supressão da expressão que autorizaria medidas inconsistentes com a carta, mas compatíveis com algum acordo internacional, esse trecho traria relevantes consequências para o contexto do comércio internacional. Cabe ressaltar, por exemplo, que uma das grandes discussões que permeia as negociações de Doha, particularmente no que tange a relação entre comércio e meio ambiente, é precisamente a forma como os chamados MEAs (Acordos Multilaterais Ambientais) e o direito da OMC interagem entre si.

O artigo 32 da Suggested Charter dos Estados Unidos, que foi debatido e adaptado durante as negociações que viriam a ocorrer entre 1946 e 1947, fora modelado conforme o artigo $4^{\circ}$ da International Convention for the Abolition of Import and Export Prohibitions and Restrictions, de 1928 (doravante, Convenção de 1928) (IRWIN; MAVROIDIS; SYKES,

${ }^{19}$ Do original: "Article 32. General Exceptions to Chapter IV. Nothing in Chapter IV of this Charter shall be construed to prevent the adoption or enforcement by any Member of measures $[\ldots]$ b. necessary to protect human, animal or plant life or health; $[\ldots]$ j. relating to the conservation of exhaustible natural resources if such measures are taken pursuant to international agreement or are made effective in conjunction with restrictions on domestic production or consumption" (U.S. Department of State, 1946, p. 24, grifo nosso) 
2008, p. 162). A leitura da redação dessa convenção permite extrair a lógica de algumas das alíneas do atual texto do GATT e seus dispositivos correspondentes ${ }^{20}$.

As negociações efetivamente ambientais das rodadas de negociação do sistema multilateral de comércio são, a despeito da antiga redação do GATT/47, bastante recentes. A falta de atenção ao tema por parte dos negociadores da ITO e do GATT pode ser atestada pela análise do texto do GATT originalmente aprovado, o qual sequer possuía o termo meio ambiente em sua redação, ainda que algumas de suas provisões, particularmente as alíneas (b) e (g) do artigo XX, tivessem impactos diretos nas medidas de comércio relativas à proteção ambiental (RAO, 2000, p. 97).

A alínea (b) do atual GATT, por exemplo, é atualmente invocada para justificar medidas contrárias ao direito da $\mathrm{OMC}$, mas tomadas com o objetivo de proteção da saúde humana, animal e vegetal ${ }^{21}$. A redação

${ }^{20}$ Essa Convenção foi assinada no contexto da Liga das Nações, em 1927, por 28 países, e algumas de suas disposições foram posteriormente tomadas para consideração no âmbito das negociações do GATT. (ORTINO, 2014, p. 6). Referido dispositivo determinava: "The following classes of prohibitions and restrictions are not prohibited by the present Convention, on condition, however, that they are not appliea in such a manner as to constitute a means of arbitrary discrimination between foreign countries where the same conditions prevail, or a disguised restriction on international trade: 1. Prohibitions or restrictions relating to public security. 2. Prohibitions or restrictions imposed on moral or humanitarian grounds. 3. Prohibitions or restrictions regarding traffic in arms, ammunition and implements of war, or, in exceptional circumstances, all other military supplies. 4. Prohibitions or restrictions imposed for the protection of public health or for the protection of animals or plants against disease, insects and harmful parasites. 5 . Export prohibitions or restrictions issued for the protection of national treasures of artistic, historic or archaeological value. 6. Prohibitions or restrictions applicable to gold, silver, coins, currency notes, banknotes or securities. 7. Prohibitions or restrictions designed to extend to foreign products the regime establish $\sim \mathrm{d}$ within the country in respect of the production of, trade in, and transport and consumption of native products of the same kind. 8. Prohibitions or restrictions applied to products which, as regards production or trade, are or may in future be subject within the country to State monopoly or to monopolies exercised under State control". (BEVANS, 1969, p. 656).

${ }^{21}$ Exemplos da utilização dessas justificativas são os casos "Thailand - Restrictions on Importation of and Internal Taxes on Cigarettes" e "United States - Restrictions on Imports of Tuna", na época do sistema GATT. O caso US - Restrictions on Imports of Tuna, paradigmático nas discussões de contenciosos ambientais no sistema GATT/ 
do artigo 4.4 da Convenção de 1928, que posteriormente deu origem à alínea (b) do artigo XX, contudo, era bem mais restritiva, excetuando das normas da dita convenção as "[...] proibições ou restrições impostas para a proteção da saúde pública ou para a proteção de animais ou plantas contra doenças, insetos e parasitas perniciosas"22. Essa redação já se encontra modificada desde a Suggested Charter dos Estados Unidos, em que a parte final do dispositivo é suprimida, e o texto presente naquele primeiro documento é o que permanece atualmente ("necessárias à proteção da saúde e da vida das pessoas e dos animais e à preservação dos vegetais" $\left.{ }^{23}\right)^{24}$.

Cabe elucidar que a redação da alínea $(\mathrm{g})$, diferentemente daquela da alínea (b), não é originária da Convenção de 1928. Segundo Matz-Lück e Wolfrum, essa alínea não parece ter algum modelo precedente em outro acordo (WOLFRUM; STOLL; SEIBERT-FORH, 2007, p. 143).

OMC, fornece um bom exemplo da utilização dessa alínea para a justificativa de medidas inconsistentes com o GATT em prol de questões ambientais. Trata-se de um litígio envolvendo o embargo à importação de produtos de atum do México imposto pelos Estados Unidos, sob, em apertada síntese, a justificativa de que a captura do atum mexicano seria prejudicial aos golfinhos. Os Estados Unidos invocaram o artigo XX(b) como exceção para o embargo, que seria contrário à proibição de restrições quantitativas (artigo XI) e ao Tratamento Nacional (artigo III) do GATT. Observa-se um claro intuito de preservação da saúde do mamífero, em uma justificativa que, pelo menos formalmente, já pode ser considerada ambientalista.

22 Do original: "Prohibitions or restrictions imposed for the protection of public health or for the protection of animals or plants against disease, insects and harmful parasites". ${ }^{23}$ Importa salientar que existe uma pequena diferença na redação original, em inglês, da versão traduzida para o português. No texto do GATT/47, artigo XX(b), e no artigo 32(b) da Suggested Charter, em inglês, a redação é a seguinte: "necessary to protext human, animal or plant life or health" (US DEPARTMENT OF STATE, 1946); enquanto no texto do GATT/47 em português, a redação é esta: "necessárias à proteção da saúde e da vida das pessoas e dos animais e à preservação dos vegetais" (MDIC, GATT/47). Na versão em português, portanto, a expressão "preservação dos vegetais" pode denotar um tom mais ambientalista, elemento que não se verifica da mesma maneira na redação em inglês. ${ }^{24}$ Para uma discussão mais aprofundada acerca do histórico da redação da alínea (b) do artigo XX do GATT, recomenda-se a leitura dos relatórios do painel e do órgão de apelação no caso United States - Import Prohibition of Certain Shrimp and Shrimp Products (DS/58). 
A alínea ( $\mathrm{g}$ ), assim como a alínea (b), do artigo XX também não foi redigida originalmente com intentos propriamente verdes. Apesar de mencionar medidas "relativas à conservação de recursos naturais esgotáveis" (MDIC, GATT/47), essa preocupação dizia respeito ao interesse econômico dos membros negociadores em manter suas reservas, especialmente no pós-guerra.

Essa conclusão pode ser extraída a partir de alguns trechos dos diálogos das negociações dos drafts, a exemplo da proposta brasileira, ainda nas discussões de Londres, sobre a possibilidade de modificar o texto do dispositivo a fim de restrição de exportações sem a necessidade de restrições ao consumo interno conjuntamente. O delegado brasileiro presente na conferência sugeriu tal modificação tendo por base a disponibilidade brasileira de manganês, que seria suficiente para consumo interno, mas, caso não houvessem limites à exportação, poderia tornar-se escassa. A sugestão não foi aceita, mantendo-se a redação no ponto em discussão, uma vez que os demais países envolvidos no tópico entenderam que o acesso aos bens de países com vastos recursos deveria ser liberalizado (E/PC/T/C.II/QR/PV/1, p. 15; E/PC/T/C.II/QR/PV/5, p. 79).

Essa leitura é corroborada pelo contexto de outras provisões presentes no texto da Carta de Havana que dispunham sobre recursos naturais: os artigos 10.2.a.i, 13.7.a.iii, 57.d e 70.3. Todos esses dispositivos tratavam de recursos naturais no contexto puramente econômico, com o fim de preservá-los para viabilizar o desenvolvimento econômico das partes ${ }^{25}$.

${ }^{25}$ A título exemplificativo, toma-se o artigo 10.2.a.i, que previa a possibilidade de estudos pelo ECOSOC dos recursos naturais de um mebro para viabilizar o seu desenvolvimento econômico e industrial: "With a view to facilitating and promoting industrial and general economic development and consequently higher standards of living, especially of those countries which are still relatively undeveloped, as well as the reconstruction of those countries whose economies have been devastated by war, and subject to any arrangements which may he entered into between the Organization and the Economic and Social Council of the United Nations and appropriate inter-governmental organizations, the Organization shall, within its powers and resources, at the request of any Member: (a) (i) study the Member's natural resources and potentialities for industrial and general economic development, and assist in the formulation of plans for such development" (WTO, Final Act of the UN Conference on Trade and Employment, p. 18). Outro exemplo é o artigo 57.d, que tratava da proteção dos recursos naturais como bens de commodities: 
Esse interesse econômico se explica pelo cenário vigente até as décadas de 1960 e 1970. Conforme Kiss e Shelton (2007, p. 33), “[...] pode-se considerar que a presente era ecológica teve início ao final da década de 1960, depois que a reconstrução do pós-Segunda Guerra Mundial levou a um desenvolvimento econômico global sem precedentes", desenvolvimento este que "[...] expandiu o uso de recursos naturais tais como água potável, ar, flora, fauna e minerais", assim como esteve associado à revolução verde na agricultura e a elevação da produção de resíduos ${ }^{26}$.

A discussão de questões ambientais até a década de 1970 era realizada de maneira pontual e, normalmente, estava relacionada a outros interesses que não aqueles ecológicos. A título exemplificativo, a paradigmática decisão arbitral do caso Trail Smelter, em 1941, estabeleceu a ideia de proibição de dano transfronteiriço ${ }^{27}$. Os danos analisados pela decisão em questão, contudo, não são mensurados tendo em vista a dimensão ecológica causada pela poluição da fundição Trail, mas sim à população, às terras e às condições de agricultura dos Estados Unidos ${ }^{28}$.

A abordagem trazida por julgados e convenções à época traduzia muito mais uma leitura do ponto de vista da soberania e dos direitos dos

"The Members recognize that inter-governmental commodity agreements are appropriate for the achievement of the following objectives: [...] (d) to maintain and develop the natural resources of the world and protect them from unnecessary exhaustion" (WTO, Final Act of the UN Conference on Trade and Employment, p. 69).

${ }^{26}$ Do original: "The present ecological era can be said to have begun at the end of the 1960s, after post-World War II reconstruction led to unprecedented global economic development. [...]It required expanded use ofexhaustible natural resources such as clean water, air, flora, fauna, and minerals" (KISS; SHELTON, 2007, p. 33).

${ }^{27}$ Assim decidiu a sentença arbitral: "under the principles of international law, as well as of the law of the United States, no State has the right to use or permit the use of its territory in such a manner as to cause injury by fumes in or to the territory of another or the properties or persons therein, when the case is of serious consequence and the injury is established by clear and convincing evidence" (ONU, 2006, p.1965).

${ }^{28} \mathrm{Na}$ decisão, lê-se, e.g, a seguinte passagem: "The Tribunal has first considered the items of indemnity claimed by the United States in its Statement (p. 52) "on account of damage occurring since january 1, 1932, covering: (a) Damages in respect of cleared land and improvements thereon; (b) Damages in respect of uncleared land and improvements thereon; (c) Damages in respect of livestock ; (d) Damages in respect of property in the town of Northport; (g) Damages in respect of business enterprises" (ONU, 2006, p. 1.920). 
Estados do que da preocupação com o desenvolvimento sustentável ou apreensões com as gerações futuras. De fato, é possível enumerar algumasconvenções que abordavam questões ecológicas, especialmente relativas à proteção de espécies da fauna e da flora, mas a redação dessas indicava uma abordagem utilitarista da matéria (KISS; SHELTON, 2007, p. 32) ${ }^{29}$. São exemplos de convenções com tal abordagem a Convention for the Protection of Birds Useful to Agriculture (1902) (KISS; SHELTON, 2007, p. 32), a Convenção para a Proteção e Preservação de Focas Peludas (1911) ${ }^{30}$ e o International Agreement for the Regulation of Whaling (1937).

Outra referência ilustrativa nesse sentido é o histórico da tutela ambiental no contexto do direito do mar.Em 1982, quando ainda não havia um grande refinamento da linguagem da proteção ambiental no cenário internacional - apesar de ter sido, como já mencionado, a partir da década de 1970 que a discussão ambiental ganhou força internacionalmente reconheceu-se, por meio da Convenção das Nações Unidas sobre Direito do Mar (UNCLOS, ou Convenção de Montego Bay), a necessidade do estabelecimento de uma ordem voltada a promover a utilização equitativa e eficiente dos seus recursos, a conservação dos recursos vivos e o estudo, a proteção e a preservação do meio marinho (BRASIL, 1995). ${ }^{31}$ Essa Convenção possui uma seção dedicada exclusivamente à "Proteção e preservação do meio marinho", que já no seu primeiro dispositivo (artigo 192)

\footnotetext{
${ }^{29}$ Ademais, conforme de Charzounes, utilitarista no sentido de que a proteção dessas espécies seria interessante do ponto de vista do homem, voltada à utilização dessas espécies pelo ser humano para fins comerciais. O objetivo era assegurar a sobrevivência das espécies para os interesses de caça, pesca e captura do ser humano (Informação verbal fornecida por Laurence Boisson de Chazournes na conferênciaLa naissance du droit international de l'environnement et sa consécration, disponibilizada pela Organização das Nações Unidas: UN Lecture Series, disponível em: <http://legal.un.org/avl/ls/Boissonde-Chazournes_EL_video_2_1.html>. Acesso em 24 mar. 2016.

${ }^{30}$ Do original Convention between the United States and Other Powers Providing for the Preservation and Protection of Fur Seals ou North Pacific Fur Seal Convention of 1911.

${ }^{31}$ Nesse sentido, Harrison (2011, p. 50) contribui: "The Convention was negotiated at a time when the protection of the environment had just become a prominent issue in international relations. Shortly before the convening of UNCLOS III, the United Nations had adopted the Stockholm Declaration on the Human Environment [...]. The Law of the Sea Convention was an opportunity to set out a comprehensive framework for the protection of the marine environment".
} 
determina como obrigação geral que "[o]s Estados tem [sic] a obrigação de proteger e preservar o meio marinho" (BRASIL, 1995).

Contudo, apesar dessa linguagem e dessa ampla proteção ambiental que raramente é encontrada em outros acordos internacionais, o embrião do sistema da UNCLOS tratava o tema de maneira bastante distinta. Em 1958, as Convenções de Genebra sobre o Direito do Mar incluíam a chamada Convenção sobre Pesca e Conservação dos Recursos Biológi$\cos ^{32}$. Tal convenção efetivamente dispunha sobre a conservação dos seres marinhos; contudo, assim era disposto por razões econômicas. O próprio preâmbulo indicava essa necessidade para que se tornasse viável a exploração marinha tendo em vista a crescente necessidade de alimentos da população humana ${ }^{33}$. Sobre a conservação das espécies biológicas do alto-mar, assim dispunha o seu artigo 2:

A expressão "conservação dos recursos biológicos de alto mar" significa, no contexto da presente Convenção, o conjunto de medidas que tornam possível o rendimento ótimo sustentável desses recursos de modo a assegurar o suprimento máximo de alimentos e outros produtos marinhos. Programas de conservação devem ser formulados de modo a garantir primordialmente o fornecimento de alimentos para consumo humano. (ONU, 1958, p. 288, grifo nosso $)^{34}$

Conforme Sands e Peel (2011, p. 210), a ideia de captura "sustentável" nos acordos relativos à captura de animais relacionava-se com uma

\footnotetext{
${ }^{32}$ Nos originais, Convention on Fishing and Conservation of the Living Resources of the High Seas (Inglês) e Convention sur la pêche et la conservation des ressources biologiques de la haute mer (Francês).

${ }^{33}$ No original: "Consideringthat the development of modern techniques for the exploitation of the living resources of the sea, increasing man's ability to meet the need of the world's expanding population for food, has exposed some of these resources to the danger of being over-exploited" (ONU, 1958).

${ }^{34}$ No original: "As employed in this Convention, the expression "conservation of the living resources of the high seas " means the aggregate of the measures rendering possible the optimum sustainable yield from those resources so as to secure a maximum supply to food and other marine products. Conservation programmes should be formulated with a view to securing in the first place a supply of food for human consumption" (ONU, 1958).
} 
"otimização" dessa exploração, para fins de interesse humano e não de preservação ecológica dos recursos. Essa leitura é corroborada pelo trecho já transcrito. Cabe ressaltar, todavia, que linguagem semelhante permanece presente ainda hoje em alguns acordos internacionais ambientais, inclusive na Convenção de Montego Bay, evidenciando que ainda hodiernamente a proteção ambiental não é de todo despida de interesses econômicos.

A partir do entendimento histórico da redação dessas alíneas, é possível compreender de forma mais concreta alguns impasses que ocorrem quando as redações dos dispositivos em questão são levadas a contenciosos da OMC. A título ilustrativo, no caso U.S. Shrimp (2001), o Órgão de Apelação da $\mathrm{OMC}$, ao interpretar a aplicabilidade do artigo $\mathrm{XX}(\mathrm{g})$ ao caso, entendeu que

[a]s palavras do Artigo XX(g), "recursos naturais exauríveis", foram, em realidade, escritas há mais de 50 anos. Elas devem ser lidas por um intérprete de tratados sob a luz de preocupações contemporâneas da comunidade de nações sobre a proteção e conservação do meio ambiente. Enquanto o Artigo XX não foi modificado na Rodada do Uruguai, o preâmbulo do Acordo da OMC mostra que, em 1994, os signatários do Acordo estavam completamente conscientes da importância e legitimidade da proteção ambiental como objetivo de políticas nacionais e internacionais. [...]

A partir da perspectiva prescrita pelo Preâmbulo do Acordo da $\mathrm{OMC}$, nós notamos que o termo genérico "recursos naturais" no Acordo XX(g) não é "estático" nesse contexto ou referência, mas, ao revés, é, "por definição, evolucionário" (WT/DS58/AB/R, p. 48, paras. 129-130)35.

${ }^{35}$ Do original: "The words of Article XX(g), "exhaustible natural resources", were actually crafted more than 50 years ago. They must be read by a treaty interpreter in the light of contemporary concerns of the community of nations about the protection and conservation of the environment. While Article XX was not modified in the Uruguay Round, the preamble attached to the WTO Agreement shows that the signatories to that Agreement were, in 1994, fully aware of the importance and legitimacy of environmental protection as a goal of national and international policy. [...] From the perspective embodied in the preamble of the WTO Agreement, we note that the generic term "natural 
Todos esses exemplos servem a elucidar o fato de que, embora as alíneas (b) e (g) do artigo XX atualmente sejam utilizadas como escusas a medidas alegadamente ambientais contrárias ao GATT, esse desígnio foi desenvolvido muito posteriormente àssuas redações originais. Em realidade, as discussões ambientais no sistema multilateral de comércio iniciaramde modo efetivotão somente a partir da década de 1970 (OMC, 1999, p. 66): conforme Weiss e Jackson (2008, p. 22), “[...] o interesse inicial da comunidade do comércio internacional em questões ambientais coincide com as preparações para a Conferência Mundial sobre o Ambiente Humano de $1972 "$ "36.

\section{De 1971 até a Rodada de Tóquio: o florescimento da proteção ambiental internacional e o GATT}

O desenvolvimento do direito internacional ambiental tomou seus contornos mais bem delineados a partir da década de 1960 (BIRNIE; BOYLE; REDGWELL, 2009, p. 1),enquanto as discussões acerca da proteção ambiental ganharam força a partir da década de 1970, particularmente com a Primeira Conferência Mundial sobre o Ambiente Humano, também conhecida como a Conferência de Estocolmo de 1972. Tal Conferência foi um divisor de águas no cenário internacional ao positivar com ampla aceitação uma declaração com 26 princípios ambientais e um Plano de Ação para políticas ambientais que seriam gerenciadas a partir daquele momento. Dentre esses princípios, merece destaque o Princípio 1, que trouxe a ideia de responsabilidade intergeracional para com o meio ambiente ${ }^{37}$.

resources" in Article XX(g) is not "static" in its content or reference but is rather "by definition, evolutionary"' (WT/DS58/AB/R, p. 48, paras. 129-130).

${ }^{36}$ Do original: "Theinitial interest of the international trade community in environmental issues coincides with the preparations for the 1972 UN Stockholm Conference on the Human Environment" (WEISS; JACKSON, 2008, p. 22).

${ }^{37}$ Assim dispõe o Princípio 1: "1. Man is both creature and moulder of his environment, which gives him physical sustenance and affordshim the opportunity for intellectual, moral, social and spiritual growth. In the long and tortuous evolution of the human race on this planet a stage has been reached when, through the rapid acceleration of science 
Além disso, foi criada o Programa das Nações Unidas para o Meio Ambiente (PNUMA), uma agência no âmbito da Organização das Nações Unidas responsável pela coordenação de ações visando à proteção ambiental, pioneira em âmbito intergovernamental (WEISS; JACKSON, 2008, p. 23).

Apesar do caráter mais expositivo da necessidade da proteção ambiental do que propriamente normativo da Declaração de Estocolmo (BIRNIE; BOYLE; REDGWELL, 2009, p. 49), foi a partir dessa conferência que as discussões ambientais ganharam significativa atenção da comunidade internacional. Em 1983, por exemplo, a Assembleia Geral das Nações Unidas iria determinar a criação de uma comissão independente que averiguasse a relação entre a proteção ambiental e o desenvolvimento econômico, a Comissão Mundial sobre o Meio Ambiente e o Desenvolvimento (WCED) ${ }^{38}$, com perspectivas realistas que pudessem balancear os dois escopos (KISS; SHELTON, 2007, p. 38).

Concomitantemente a todo esse processo, ocorria um amplo desenvolvimento da regulação ambiental internacional (KISS; SHELTON, 2007, p. 38), assim como das discussões internacionais sobre o tema. Emergia, de modo particular, a percepção de que a necessidade de proteção ambiental perpassava também a regulação do comércio internacional. Naturalmente, essa mudança de perspectiva nas relações internacionais influenciou as negociações do sistema multilateral de comércio.

Os reflexos puderam ser observados nos trabalhos preparatórios à Conferência de Estocolmo. As partes contratantes do GATT foram designadas, já em 1971, para contribuir com o encontro elaborando um estudo com relação ao liame entre proteção ambiental e comércio. Assim, no mesmo ano, o Secretariado do GATT formulou um estudo intitulado

and technology, man has acquired the power to transform his environment in countless ways and on an unprecedented scale. Both aspects of man's environment, the natural and the man-made, are essential to his well-being and to the enjoyment of basic human rights the right to life itself" (ONU, 1972).

38 World Commission on Environment and Development, também conhecida como Bruntland Comission. 
Industrial Pollution Control and International Trade ${ }^{39}$, voltado especialmente à análise do impacto de medidas protetivas ao meio ambiente como barreiras disfarçadas ao livre comércio (RAO, 2000, p. 95). A partir desse requerimento, a discussão acerca da interação entre proteção ambiental e o sistema multilateral de comércio entrou oficialmente no cenário de negociações do grupo do GATT, de modo que os delegados dos países contratantes começaram a discutir acerca da necessidade de intensificar os estudos nesse campo ${ }^{40}$.

A questão suscitouinicialmente algumas controvérsias, dada a novidade do assunto. Alguns delegados acreditavam que outros órgãos internacionais já tratavam do tema, outros indagavam se o assuntosequer estava dentro das competências do GATT. Uma delegação inclusive ques-

${ }^{39} \mathrm{Cf}$. Indutrial Pollution Control and International Trade - Note by the Secretariat: "Early this year, the Secretary-General of the UN Conference on the Human Environment, Mr. M. Strong, requested GATT's participation in the preparatory work for this Conference to be;held in Stockholm in 1972. It was agreed that the GATT secretariat would survey certain issues that national anti-pollution measures might raise for international trade, having regard to the provisions and objectives of the General Agreement, and present the conclusions of such a survey in a paper to be included in the basic documentation for the Conference" (L/3538, 1971, p. 1). O mencionado documento está anexo a essa declaração.

${ }^{40}$ A reação inicial acerca do relatório parece ter sido suscitada por provocações do Diretor Geral do GATT à época, Olivier Long: "The Director-General, referring to the note entitled "Industrial Pollution Control and International Trade" (document L/3538), stated that this study had been prepared by the secretariat at the request of Mr. Strong, Secretary-General of the United Nations Conference on the Human Environment, as a contribution to the preparatory work for the Conference to be held in Stockholm in 1972. The study did not commit the CONTRACTING PARTIES in any way. As he had indicated in the Council meeting of June, it would seem desirable for the CONTRACTING PARTIES to follow these matters closely from the beginning from the aspects directly concerning them, in other words, to consider the implications of industrial pollution control on international trade, especially with regard to the application of the provisions of the General Agreement. Contracting parties carried a special responsibility in this area. They had to ensure that the efforts of governments to combat pollution did not result in the introduction of now barriers to trade or impede the removal of existing barriers. It was, therefore, perhaps worth considering whether it would not be useful for the CONTRACTING PARTIES to set up a flexible mechanism which could be used at the request of contracting parties if the need arose. Several representatives expressed agreement that the GATT had certain responsibilities in dealing with the implications of industrial pollution control on international trade" (C/M/73, 1971, p. 12). 
tionou a possibilidade de tal tema interferir no desenvolvimento do comércio em países em desenvolvimento (C/M/73, 1971, p. 13).

Apesar das contestações apresentadas, foi nesse contexto, ainda em 1971, que os membros do GATT decidiram pela criação de um grupo conhecido como Group on Environmental Measures and International Trade (EMIT) (C/M/74, 1971, p. 3-4), que se reuniria sob o requerimento dos membros da instituição. Algumas das preocupações levantadas com a possibilidade deinserção do tema foram mitigadas diante dos termos de referência do grupo, que, por exemplo, delimitou as discussões ambientais ao contexto relevante ao Acordo Geral Sobre Tarifas e Comércio. Determinou-se, ainda, que as questões deveriam levar em consideração os problemas particulares dos países em desenvolvimento ${ }^{41}$.

A função do EMIT era, essencialmente, examinar questões relevantes ao GATT relativas a medidas de controle de poluição e proteção do "meio ambiente humano" (protect human environment), considerando as particularidades dos PEDs, e reportar suas atividades ao Conselho do GATT $^{42}$. Nenhum requerimento, contudo, foi efetivado até 1991, quando uma solicitação do grupo EFTA (European Free Trade Association) foi realizada, solicitando a convocação do $\operatorname{EMIT~(L/6896,~1991,~p.~6)~}{ }^{43}$.

A rodada de negociações que se seguiu a essa época de florescimento de discussões ambientais no cenário internacional foi a Rodada de Tóquio (1973-1979). Esta última foi oficialmente aberta em 14 de setembro de 1973, tendo presente delegações de 99 países, que na época representavam $90 \%$ do comércio mundial ${ }^{44}$. Esse ciclo marcou o processo

${ }^{41}$ Cf. L/6896 (1991, p. 5 e C/M/74, 1971, p. 4 e ss).

${ }^{42}$ Do original: "The CONTRACTING PARTIES [...] decide to establish a Group whose main functions would be: 1 . to examine upon request any specific matters relevant to the trade policy aspects of measures to control pollution and protect human environment especially with regard to the application of the provisions of the General Agreement taking into account the particular problems of developing countries; 2 . to report on its activities to the Council" (C/M/74, 1991, p. 4).

${ }^{43}$ Cf. ainda Rao, 2000, p. 95.

${ }^{44}$ Sobre as mudanças realizadas pelo Tokyo Round no sistema GATT, ver VENTURINI, Gabriela. Il GATT dopo il Tokyo Round: bilateralismo, multilateralismo e cooperazione. Diritto comunitario e degli scambi internazionali, 1980, p. 395 ss; FLORY, Thiébaut. 
de negociações no âmbito do GATT principalmente por dois fatores: foi efetivamente iniciada a batalha contra os obstáculos não tarifários ${ }^{45}$, instrumento que teve uma proliferação não indiferente após a Rodada Kennedy, e por ter sido o período em que foram emanados os "códigos" sobre as principais matérias regulamentadas pelo Acordo Geral ${ }^{46}$.

Nesse contexto, passou-se a considerar com maior atenção a extensão do impactoque as medidas de proteção ambiental tomadas pelos países poderiam significar comopossíveis obstáculos ao comércio internacional, ainda que poucas medidas efetivamente ligadas à interação desses dois campos tenham sido tomadas (RAO, 2000, p. 96). Cabe ressaltar que, sendo as negociações do GATT um fórum para o sistema multilateral de comércio, o principal enfoque da interação entre comércio internacional e meio ambiente foi, justamente, em que medida a proteção ambiental significaria um obstáculo aos acordos até então firmados.

Dentre esses acordos negociados na Rodada de Tóquio, talvez aquele com uma implicação mais expressiva para a temática ambiental tenha sido o Acordo Sobre Barreiras Técnicas ao Comércio (TBT), então conhecido como Standards Code. Posteriormente aprimorado na Rodada do Uruguai, o objetivo do Standards Code era o de que, na medida do possível, padrões e regulamentos técnicos impostos pelos países tivessem

Les accords du Tokyo Round et la réforme du système commercial multilatéral du GATT. Annuaire Français de Droit International, n. ${ }^{\circ} 25$ (1979), p. 580 ss; FLORY, Thiébaut. Les accords du Tokyo Round du GATT et la réforme des procédures de règlement des différends dans le système commercial interétatique. Revue Génerale de Droit International Public, n. 86 (1982), p. 235 ss; e, McRAE, Donald et THOMAS, Christophe. The GATT and Multilateral Treaty Making: The Tokyo Round. American Journal of International Law, n. 77 (1983), p. 51 ss.

${ }^{45}$ Sendo latente o insucesso da aplicação do artigo XI do Acordo Geral de 1947 - que proibia a utilização de instrumentos deste tipo quando se referia às restrições quantitivas -, os países participantes da rodada, ao aprovarem a Declaração de Tokyo, no início da reunião, afirmaram que as negociações deveriam "reduzir ou eliminar as medidas não tarifárias ou, no caso em que isto não fosse apropriado, reduzir ou eliminar os efeitos de restrições ou de distorsões e sujeitar estas medidas a uma disciplina internacional mais eficaz" (parágrafo 3, letra b). Ver, Idem, p. 153.

${ }^{46}$ COMBA, Andrea. Il Neo Liberismo Internazionale. Strutture Giuridiche a Dimensione Mondiale. Dagli Accordi di Bretton Woods all'Organizzazione Mondiale del Commercio. Milano: Giuffrè, 1994, p. 173. 
o mínimo possível de efeitos adversos ao livre comércio ${ }^{47}$. Regulamentos técnicos e normas podem representar barreiras não tarifárias na medida em que, com o intento de proteger algum bem relevante, o país regulador venha a imporrestrições à importação ou exportação de produtos.

A relação dos regulamentos técnicos com a questão ambiental é evidente e, inclusive, está determinada de modo textual.Esse acordo assegura expressamente, conforme a atual redação do artigo 2.2 do TBT, a possibilidade de estipulação de regulamentos técnicos com o objetivo de proteção à saúde ou vida animal ou vegetal ou do meio ambiente, dentre outros escopos, desde que "[...] não sejam elaborados, adotados ou aplicados com a finalidade ou o efeito de criar obstáculos técnicos ao comércio internacional" (MDIC, TBT).

Em outras palavras, a proteção ao meio ambiente é expressa como um objetivo legítimo que justifica a imposição de regulamentos técnicos, ou seja, barreiras não tarifárias ao comércio internacional (ainda que devendo ser tomadas nos termos do acordo). De igual maneira, a redação do preâmbulo do Standards Code é também digna de nota por, em 1972, indicar a vontade dos contratantes em desenvolver normas em matéria de proteção ambiental ${ }^{48}$. Cabe ressaltar que proteção ambiental ("environmental protection") não foi uma expressão utilizada em momento algum no contexto da redação do GATT/47, da onde se observa já uma mudança de perspectiva, provavelmente em decorrência do cenário internacional relativo a questões ecológicas na década de 1970 .

Efetivamente, a relevância incidental desse acordo para a questão ambiental é tão significativa que ainda hoje se discutem os seus reflexos em problemáticas como o ecolabelling e os métodos de processo e produção (PPMs) ambientais ${ }^{49}$. A discussão sobre PPMs, um tópicos centrais

\footnotetext{
${ }^{47}$ Sobre o escopo inicialmente projetado pelas partes contratantes, cf. L/3496, pp. 53 e ss. 48 A título exemplificativo, um verso da primeira versão da redação do preâmbulo determinava: "The adherents to this Code, [...] Desiring to encourage governments to develop international standards particularly in the fields of safety, health and environmental protection; [...]" (Spec(72)103, 1972, p. 9).

${ }^{49}$ A OCDE apresenta a seguinte definição para PPMs: "The term PPMs refers to processes and production methods and is defined as the way in which products are manufactured
} 
da corrente Rodada de Doha, já existia, ainda que tímida, em painéis do sistema GATT. Contenciosos como Spain - Unroasted Coffee $e^{50}(1981)$ e US - TunaI ${ }^{51}$ (1991) abordaram a questão, ainda que indiretamente, mas apenas no âmbito do Acordo Geral sobre Tarifas e Comércio. Atualmente, o Acordo sobre Barreiras Técnicas ao Comércio traz menção expressa a métodos de processo e produção ${ }^{52}$ em diversas passagens de seu texto. Essa menção, na versão do Standards Code (1971), estava presente apenas em dispositivo que determinava a necessidade de se conceder tempo aos produtores dos países exportadores para que pudessem "adaptar seus produtos ou métodos de produção aos requerimentos dos países importadores" 53 .

Atualmente, caminha-se no sentido de um crescente refinamento da discussão sobre PPMs. O contencioso US - Tuna I,que iniciou com uma reclamação, em 1991, no âmbito do GATT, teve tantos desdobramentos, cada vez mais complexos, que viu sua mais recente decisão prolatada em novembro de 2015. A disputa teve início com um embargo imposto pelos Estados Unidos ao atum proveniente do México, porque a forma com a qual esse atum era capturado não respeitava uma legislação interna dos Estados Unidos que estabelecia critérios para pesca com o objetivo de proteger a população de mamíferos marinhos, especialmente golfinhos.

Essa disputa é paradigmática no contexto dos PPMs, por levar à apreciação dos mecanismos de solução de controvérsias do sistema multi-

or processed and natural resources extracted or harvested" (OECE, 1997, p. 7). Sobre o tema, cf. (CHARNOVITZ), 2002; (HOWSE) E (REGAN), 2000; (CONRAD), 2012.

50 Título completo: Spain - Tariff treatment of unroasted coffee (L/5135)

${ }^{51}$ Título completo:United States - Restrictions on imports of tuna (DS21/R)

52 A menção consta, por exemplo, na definição de regulamentos técnicos prevista pelo Anexo 1 do Acordo: o regulamento técnico “[...] [p]oderá também tratar parcial ou exclusivamente de terminologia, símbolos, requisitos de embalagem, marcação ou rotulagem aplicáveis a um produto, processo ou método de produção" (MDIC, TBT).

${ }^{53}$ Traduzido do original: "Except where there are urgent problems of public safety, health, environmental protection or national security, adherents shall allow a reasonable interval to elapse before bringing mandatory standards into force, in order to allow time for producers in exporting countries to adapt their products or methods of production to the requirements of the importing country." (GATT, 72(103)). Essa disposição permanece, mutatis mutandis, no artigo $2^{\circ}$ do TBT (MDIC, TBT) 
lateral de comércio se a forma com a qual um bem é produzido (no caso, se a proteção a golfinhos) pode ser levada em consideração na hora de se estabelecer um tratamento diferencial entre um produto e outro. À época, o litígio foi resolvido por meio do estabelecimento de um panel (ou grupo especial), o mecanismo do qual dispunha o sistema GATT para a resolução de litígios, mas os Estados Unidos sequer se adequaram à decisão prolatada, que, nesse sistema, era de observância facultativa.Contudo, com o amplo arcabouço normativo aportado pela OMC, pela consolidação dos demais códigos para além do GATT e com o refinamento das controvérsias no sistema multilateral de comércio, o litígio entre os dois países bateu na porta da OMC, em 2008 (tanto que o procedimento ganhou a alcunha de US - Tuna II), e teve sua mais recente decisão prolatada em novembro de 2015.

Nessa nova versão do caso, o Acordo Sobre Barreiras Técnicas ao Comércio, sucessor do Standards Code, foi incorporado à reclamação, indo-se muito além do GATT. Inclusive, a decisão do OAp sobre o mérito da disputa, em 2012, centrou-se na discussão dos dispositivos do TBT, restando prejudicada a análise das violações do GATT. Vê-se, portanto, a contribuição que um acordo, negociado pela primeira vez no início da década de 1970, tem em litígios atuais.

Outra importante contribuição do Standards Code foi determinar a possibilidade de utilização de um grupo de experts técnicos para averiguar a necessidade do regulamento ou norma para o fim declarado pelo país regulador (L/6896, 1991, p. 14). Essa possibilidade veio posteriormente corroborada pelo Entendimento do mecanismo de solução de litígios do sistema $\mathrm{OMC}^{54}$, mas, à época do sistema GATT, era inovadora.

\footnotetext{
${ }^{54} \mathrm{O}$ artigo 13 do Entendimento Relativo às Normas e Procedimentos sobre Solução de Controvérsias dispõe que "[t]odo grupo especial terá direito de recorrer à informação e ao assessoramento técnico de qualquer pessoa ou entidade que considere conveniente" e que “[o]s grupos especiais poderão buscar informação em qualquer fonte relevante e poderão consultar peritos para obter sua opinião sobre determinados aspectos de uma questão. Com relação a um aspecto concreto de uma questão de caráter científico ou técnico trazido à controvérsia por uma parte, o grupo especial poderá requerer um relatório escrito a um grupo consultivo de peritos. As normas para estabelecimento de tal grupo e seus procedimentos constam do Apêndice 4" (MDIC, ESC). O caso US - Shrimp, cujo procedimento foi iniciado em 1996, já no contexto do Órgão de Controvérsias da OMC,
} 
A década de 1970 e a Rodada de Tóquio não trouxeram reformas significativas à tutela jurídica do meio ambiente no contexto do GATT. $\mathrm{O}$ que se observou foi mais propriamente uma mudança de paradigma, cujas sementes, lançadas particularmente pela Conferência de Estocolmo, iriam repercutir ao longo das duas décadas seguintes. O Standards Code e o relatório Industrial Pollution Control and International Trade foram meros indícios de uma discussão que viria a tomar contornos mais bem delineados durante a Rodada do Uruguai e repercutiriam até a atual Rodada de Doha.

\section{Conclusão}

As origens do sistema multilateral de comércio, desde a instituição do sistema GATT, em 1947, constituem uma pertinente fonte para a compreensão da atual tutela jurídica do meio ambiente no sistema OMC. Como explicitado na Introdução, o objetivo deste artigo, portanto, foi analisar o desenvolvimento dessa tutela durante o período de 1947-1979, ou seja, até o final da Rodada de Tóquio.

A partir dessa leitura, foi possível verificar que, devido ao fato de que a discussão sobre a proteção do meio ambiente ainda não ganhara projeção internacional, a incorporação de acordos e dispositivos relativos à tutela ambiental foi incipiente no período aquianalisado. Durante o período objeto de análise neste artigo, o diálogo da tutela ambiental com o sistema de comércio internacional foi tímida, especialmente até a década de 1970. Anteriormente a essa data, textos de acordos internacionais, inclusive de dispositivos do GATT, referentes à proteção de recursos naturais, eram pautados em interesses eminentemente utilitaristas do meio ambiente.

é um exemplo de controvérsia a envolver questões ambientais, cujo painel lançou mão do uso de experts. A controvérsia envolvia a discussão acerca da proteção de tartarugas marinhas e, portanto, o grupo especial montado recorreu a essa técnica para averiguar quais espécies de tartarugas marinhas efetivamente estavam sob risco. No caso em questão, nenhuma das partes havia solicitado o uso de experts, mas o painel, conforme as disposições contidas no artigo 13 do ESC, tomou essa iniciativa. Sobre o uso de experts no mecanismo de solução de controvérsias da OMC, cf. Pauwelyn (2002). 
A análise, contudo, está longe de ser despicienda, uma vez que entender a origem de termos que hodiernamente são invocados para justificar medidas ambientais é um instrumento que possibilita a compreensão das dificuldades de sua aplicação prática, como acontece, por exemplo,no que se refere àaplicabilidade das alíneas (b) e (g) no âmbito dos contenciosos da $\mathrm{OMC}$. Ao longo dos anos que sucederam à Conferência de Estocolmo e a Rio-92, a prática acabou por dar novos entendimentos a dispositivos originalmente concebidos com intentos distintos, como se percebeu da leitura do caso U.S. - Shrimp.

Ademais, a ativa participação dos membros do GATT nos trabalhos preparatórios da Conferência de Estocolmo e a criação do EMIT foram o embrião das extensas discussões ambientais que iriam se desenrolar ao longo das décadas seguintes. É nas Rodadas do Uruguai e de Doha que essa interação entre a emergência internacional da proteção ambiental e o sistema multilateral de comércio seriam sentidas com mais afinco.

\section{Documentos do GATT}

E/PC/T/C.II/QR/PV/1. Verbatim Report of the First Meeting of the SubCommittee of Committee II on Quantitative Restrictions and Exchange Control held at Church House, Westminster. 11.11.1946.

E/PC/T/C.II/QR/PV/5.Verbatim Report of the First Meeting of the SubCommittee of Committee II on Quantitative Restrictions and Exchange Control held in Room 230. 18.11.1946.

L/3538. Industrial Pollution Control and International Trade - Note by the GATT Secretariat. 09.06.1971.

L/3496. Committee on Trade in Industrial Products.10.02.1972.

$\mathbf{C} / \mathbf{M} / 73$.Minutes of Meeting - Held in the Palais des Nations, Geneva.06-07.10.1971.

C/M/74.Minutes of Meeting - Held in the Palais des Nations, Geneva.09.11.1971. 
Spec72(103). Drafting Group on Standards - Note on Meeting of September/October 1972.

L/6896. Trade and Environment - Factual Note by the Secretariat.18.11.1991.

\section{Referências}

BEVANS, Charles I..Abolition of Import and Export Prohibitions and Restrictions (1928). Treaties and Other International Agreements of the United States of America, 1776-1949. Volume 2: Multilateral, 19181930. 1928. p. 651-682. Washington, 1969.Disponível em: $<$ http://www. loc.gov/law/help/us-treaties/bevans/m-ust000002-0651.pdf $>$. Acesso em: 13 jan. 2016.

BIRNIE, Patricia; BOYLE, Alan; REDGWELL, Catherine.

International Law and the Environment. 3rd ed. Oxford: Oxford University Press, 2009.

BRASIL. Decreto n. 1.530, de 1995. Convenção das Nações Unidas Sobre O Direito do Mar (UNCLOS). Brasília, DF, 22 jun. 1995. Disponível em: < http://www2.camara.leg.br/legin/fed/decret/1995/ decreto-1530-22-junho-1995-435606-publicacaooriginal-1-pe.html>. Acesso em: 26 abr. 2016.

CAMERON, James; GRAY, Kevin R..Principles of International Law in the WTO Dispute Settlement Body. International and Comparative Law Quarterly, Cambridge, v. 50, n. 2, p. 248-298, abril, 2001.

CHARNOVITZ, Steve. The Law of Environmental 'PPMs' in the WTO: Debunking theMyth of Illegality. Yale Journal of International Law, New Haven, v. 59, 2002. Disponível em: <http://scholarship.law.gwu. edu/cgi/viewcontent.cgi? article $=1451 \&$ context=faculty_publications $>$. Acesso em: 8 maio 2014.

CONRAD, Christiane R. Processes and Production Methods (PPMs) in WTO Law: Interfacing Trade and Social Goals. Paperback edition. 
Cambridge: Cambridge University Press, 2013. (Cambridge International Trade and Economic Law)

DAL RI JR., Arno. História do direito internacional: comércio e moeda, cidadania e nacionalidade. Florianópolis: Fundação Boiteux, 2004.

HARRISON, James. Making the Law of the Sea: a Study in the Development of International Law. Cambridge: Cambridge University Press, 2011. (Cambridge studies in international and comparative law) HOEKMAN, Bernard M.; MAVROIDIS, Petros C.The World Trade Organization: law, economics and politics. New York: Routledge, 2007. (Global Institutions Series)

HOWSE, Robert; REGAN, Donald.The product/process distinction - an illusory basis for disciplining 'unilateralism' in trade policy. European Journal of International Law, [S.l.], v. 11, n. 2, p. 249-289, 2000.

IRWIN, Douglas A.; C. MAVROIDIS, Petros; SYKES, Alan O. The Genesis of the GATT. New York: Cambridge University Press, 2008. KISS, Alexandre; SHELTON, Dinah.Guide to International Environmental Law. Leiden: Brill Academic Publishers, Inc, 2007. MDIC Ministério do Desenvolvimento, Indústria e Comércio Exterior. Acordo Constitutivo da Organização Mundial do Comércio. 1994. Disponível em: <http:/www.mdic.gov.br/arquivo/secex/omc/acordos/ portugues/02estabeleceomc.pdf>. Acesso em: 26 ago. 2014.

. GATT/47 - Acordo Geral sobre Tarifas e Comércio. [2015]. Disponível em: <http://www.desenvolvimento.gov.br/sitio/interna/ interna.php? area $=5 \&$ menu=367\& $\mathrm{refr}=366>$. Acesso em: 29 mar.2015.

. GATT/94 - Acordo Geral sobre Tarifas e Comércio. 1994. Disponível em: <http://www.desenvolvimento.gov.br/sitio/interna/ interna.php? area $=5 \&$ menu $=367 \&$ refr=366> . Acesso em: 29 mar. 2015.

OECD - ORGANISATION FOR ECONOMIC CO-OPERATION AND DEVELOPMENT. Processes and Production Methods (PPMs): Conceptual Framework and Considerations on use of PPM- 
Based Trade Measures.1997. Disponível em: <http://www.oecd. org/officialdocuments/publicdisplaydocumentpdf/?cote=OCDE/ GD(97)137\&docLanguage=En>. Acesso em: 2 jun. 2014.

ORGANIZAÇÃO DAS NAÇÕES UNIDAS (ONU). Convention on Fishing and Conservation of the Living Resources of the High Seas. 1958. Disponível em: <https://treaties.un.org/doc/Publication/UNTS/ Volume\%20559/volume-559-I-8164-English.pdf > . Acesso em: 26 abr. 2016.

.Declaration of the United Nations Conference on the Human Environment.1972. Disponível em: $<$ http://legal.un.org/avl/ha/dunche/ dunche.html\#3>. Acesso em: 15 jan. 2016.

. Trail Smelter case (United States v. Canada). In: ORGANIZAÇÃO DAS NAÇÕES UNIDAS (ONU). Reports of International Arbitral Awards, [S.l.],v. III, 2006.p. 1.905-1.982.

. Agenda 21. Brasília, DF: Câmara dos Deputados, 1995. (Ação Parlamentar). Disponível em: <http://www.onu.org.br/rio20/img/2012/01/ agenda21.pdf $>$. Acesso em: 13 nov. 2015.

. Sustainable Development: From Brundtland to Rio 2012. New York: United Nations Headquarters, 2010. Disponível em: $<$ http:// www.un.org/wcm/webdav/site/climatechange/shared/gsp/docs/GSP16_Background $\% 20$ on\%20Sustainable\%20Devt.pdf $>$. Acesso em: 31 nov. 2015 .

ORTINO, Federico. Liberalization of trade goods in the EEC: Origin and Early Evolution. In: CREMONA, Marise et al. Reflections on the Constitutionalisation of International Economic Law: Liber Amicorum for Ernst-Ulrich Petersmann. Leiden-Boston: Martinus Nijhoff, 2014. p. 3-20.

PAUWELYN, Joost. The Use of Experts in WTO Dispute Settlement. The International And Comparative Law Quarterly, Cambridge, v. 51, n. 2, p. 325-364, abr. 2002.

SANDS, Phillipe; PEEL, Jacqueline.Principles of International Environmental Law. $3^{\text {rd }}$ ed. Cambridge: Cambridge University Press, 2011. 
STOLL, Peter-Tobias; SCHORKOPF, Frank.World Economic Order, World Trade Law. Leiden: Martinus Nijhoff, 2006. (Max Planck Commentaries on World Trade Law)

\section{U.S. DEPARTMENT OF STATE. Suggested Charter for an}

International Trade Organization of the United Nations. Washington: Department of State, 1946.

\section{VAN DEN BOSSCHE, Peter. The Law and Policy of the World} Trade Organization: text, cases and materials. Cambridge: Cambridge University Press, 2005.

VANGRASSTEK, Craig. The History and Future of the World Trade Organization. Genebra: WTO Publications, 2013. Disponível em: $<$ http://www.wto.org/english/res_e/booksp_e/historywto_e.pdf $>$. Acesso em: 15 set. 2014.

WEISS, Edith Brown; JACKSON, John H.The Framework for Environment and TradeDisputes. In: WEISS, Edith Brown; JACKSON, John H.; BERNASCONI-OSTERWALDER, Nathalie. Reconciling environment and trade. $2^{\text {nd }}$ ed. Leiden: Martinus Nijhoff Publishers, 2008.

WORLD BANK. About the World Bank. 2015. Disponível em: < http:// www.worldbank.org/en/about>. Acesso em: 15 set. 2014.

WORLD TRADE ORGANIZATION (WTO). Final Act of the UN Conference on Trade and Employment and Related Documents. Lake Success, 1948. Disponível em: <https:/www.wto.org/english/ docs_e/legal_e/havana_e.pdf $>$. Acesso em: 18 jan. 2016.

Decision on Trade and Environment. Marrakesh, 1994. Disponível em: < https://www.wto.org/english/docs_e/legal_e/56-dtenv. pdf $>$. Acesso em: 7 dez. 2015.

GATT Analytical Index. 2012. Disponível em: <https://www. wto.org/english/res_e/booksp_e/gatt_ai_e/gatt_ai_e.htm >. Acesso em: 31 jan. 2016.

. Relevant WTO provisions: text of 1994 decision. 2015a.

Disponível em: $<$ https://www.wto.org/english/tratop_e/envir_e/issu5_e. htm>. Acesso em: 7 dez. 2015. 
. Items of focus: the regular CTE's Doha assignment. $2015 \mathrm{~b}$.

Disponível em: $<$ https://www.wto.org/english/tratop_e/envir_e/cte_ doha_e.htm>. Acesso em: 7 dez. 2015.

\section{. The Committee on Trade and Environment ('regular' CTE).}

2015c. Disponível em: <https://www.wto.org/english/tratop_e/envir_e/ wrk_committee_e.htm>. Acesso em: 7 dez. 2015.

. Negotiations on trade and the environment. 2016a.

Disponível em: <https://www.wto.org/english/tratop_e/envir_e/envir_ negotiations_e.htm>. Acesso em: 31 jan. 2016.

. What is the WTO? 2016b. <http://www.wto.org/english/ thewto_e/whatis_e/inbrief_e/inbr00_e.htm>. Acesso em 23 set. 2014. WT/DS58/AB/R. United States - Import Prohibition of Certain Shrimp and Shrimp Products.Disponível em: $<$ https://www.wto.org/english/ tratop_e/dispu_e/cases_e/ds58_e.htm>. Acesso em: 24 jun. 2016.

Arno Dal Ri Jr. é doutor em Direito Internacional Econômico pela Università Luigi Bocconi de Milão, com pós-doutorado pela Université Paris 1 (PanthéonSorbonne). Professor de Teoria e História do Direito Internacional na Universidade Federal de Santa Catarina.

E-mail: arnodalri@gmail.com.

Endereço profissional: Universidade Federal de Santa Catarina, Centro de Ciências Jurídicas, Trindade, Florianópolis, SC. CEP: - 88040-900.

Mariana Clara de Andrade é mestranda em Direito e Relações Internacionais pela Universidade Federal de Santa Catarina; membro do Grupo de Pesquisa em Direito Internacional Ius Gentium (UFSC/CNPq).

E-mail: mariana.clara@live.com.

Endereço profissional: Universidade Federal de Santa Catarina, Centro de Ciências Jurídicas, Trindade, Florianópolis, SC. CEP: 88040-900. 
